\title{
Modified Nickel Nanowires for Electro-Catalytic Oxidation of Formaldehyde in Alkaline Solutions ${ }^{\dagger}$
}

\author{
Špela Trafela ${ }^{1,2 * *}$ and Kristina Žužek Rožman ${ }^{1,2}$ \\ 1 Department for Nanostructured Materials, Jožef Stefan Institute, Jamova 39, Si-1000 Ljubljana, Slovenia \\ 2 Jožef Stefan International Postgraduate School, Jamova 39, Si-1000 Ljubljana, Slovenia \\ * Correspondence: spela.trafela@ijs.si \\ † Presented at the 7th International Symposium on Sensor Science, Napoli, Italy, 9-11 May 2019.
}

Published: 29 August 2019

\begin{abstract}
A Ni nanowires-based electrodes for formaldehyde ( $\mathrm{HCHO})$ detection were fabricated via a template-assisted electrodeposition. The as-deposited Ni nanowires (NWs) were characterized by scanning electron microscope (SEM). In order to form an active redox couple of $\mathrm{Ni}(\mathrm{OH})_{2} / \mathrm{NiOOH}$ on the surface of nanowires, the Ni NWs were electrochemically modified in $0.5 \mathrm{~mol} \mathrm{~L}^{-1} \mathrm{KOH}$ using cyclic voltammetry. The presence of $\mathrm{Ni}(\mathrm{OH})_{2} / \mathrm{NiOOH}$ on the surface of $\mathrm{Ni} \mathrm{NWs}$ was confirmed by transmission electron microscopy (TEM). Furthermore, the ability of modified Ni NWs-based electrode (i.e., receptor element) was investigated for $\mathrm{HCHO}$ electro-oxidation in alkaline media via cyclic voltammetry and amperometry. The fabricated Ni NWs-based electrode exhibited fast response (3s), good selectivity, a high sensitivity and low limit of detection $0.8 \mu \mathrm{mol} \mathrm{\textrm {L } ^ { - 1 }}$.
\end{abstract}

Keywords: formaldehyde; Ni nanowires electrode; electro-oxidation; electro-catalysis

\section{Introduction}

Formaldehyde $(\mathrm{HCHO})$ is a very important compound in the fuel cell industry. It is also one of the initial products of the methanol oxidation, which has technological significance in industrial catalytic processes [1]. It was found in many products, to which many industrial workers and customers are exposed on a daily basis. Exposure to formaldehyde leads to blindness, respiratory diseases, cause cancer and in the worst cases, death [2]. Currently, several analytical techniques (spectroscopic and chromatographic) have been applied for detection of $\mathrm{HCHO}$, such as high performance liquid chromatography, gas chromatography, spectroscopic and colorimetric methods; which are impractical, expensive and time-consuming. Therefore, on site monitoring of $\mathrm{HCHO}$ is very important from the perspective of controlling the industrial process, as well from protecting employees to being exposed to toxic $\mathrm{HCHO}$.

The analysis that enables fast detection and high selectivity of $\mathrm{HCHO}$ is electrochemical detection which includes the catalysis of the electrochemical reactions, provided by nanostructured electrodes [3] with the unique physical, chemical and electrical properties. The combination of the catalytic properties with the unique properties of the nanomaterial enables the construction of highly sensitive sensor systems. Many different kinds of nanomaterials (nanoparticles, nanowires, nanotubes, etc. [4,5]) have been used for constructing electrochemical sensors. The use of nanomaterials with the inherent high surface area results in lower detection limits and improved specificity. In recent years, selection of the catalytic materials for $\mathrm{HCHO}$ detection, has been the subject of many studies and optimizations. Most of the catalytic materials were based on noble metal ( $\mathrm{Pt}, \mathrm{Pd}, \mathrm{Au}, \mathrm{Ag}$, etc.) nanomaterials, due to their amazing catalytic properties. But, the limiting factors is that noble metals-based electrodes are quickly poisoned by adsorbed intermediate (carbon monoxide). Furthermore, these metals are not economical for practical and industrial applications due to their high price. Among these, nickel is an interesting metal, as it is low cost and relatively abundant material that is often used in various 
industrial applications such as electrochemical sensors, secondary battery electrodes, oxidation of organic compound and the electrochemical treatment of wastewater [6]. It has been shown that nickel electrodes are of interest as modifying agents because in alkaline media nickel redox species $\left(\mathrm{Ni}(\mathrm{OH})_{2} / \mathrm{NiOOH}\right)$ show high catalytic activity towards oxidation of $\mathrm{HCHO}$ [7].

\section{Materials and Methods}

The cyclic voltammetry and amperometry were carried out using a potentiostat/galvanostat Gamry Reference 600 equipped with PHE 200 software at room temperature. Figure 1 (left) presents a standard three-electrode system that was used during the experiments. The reference electrode was an $\mathrm{Ag} / \mathrm{AgCl} / 3.5 \mathrm{M} \mathrm{KCl}$ (HANA Instruments GmbH-type HI5311). A circular platinum mesh was used as a counter electrode. The diameter of the circular opening in a Teflon cell, where the working electrodes were exposed to the electrolyte, is $0.5 \mathrm{~cm}$ (the calculated corresponding area is $0.196 \mathrm{~cm}^{2}$ ).

(a) Electrodeposition of Ni nanowires (NWs) (Figure 1a): The Ni NWs were prepared by templateasissted electrodeposition into a commercially available anodized aluminium oxide (AAO) (Whatman Anopore, the pore diameter was found to be $200 \pm 50 \mathrm{~nm}$. A pore density of $1 \times 10^{9} \mathrm{~cm}^{-2}$ was calculated from SEM images). The bottom part of AAO template was sputtered with a 600-nm-thick Au conductive layer. Prior to the electrodeposition of the Ni NWs, the bottom branched part of the pores was filled with Au NWs from commercially available gold electrolyte (Ecolyt SG100). Ni nanowires were electrodeposited by applying a constant potential of $-1.0 \mathrm{~V}$ for $1200 \mathrm{~s}$. The electrolyte for the deposition of Ni NWs was composed of $0.2 \mathrm{M} \mathrm{NiSO}_{4} \cdot 6 \mathrm{H}_{2} \mathrm{O}$ and $0.1 \mathrm{M} \mathrm{H}_{3} \mathrm{BO}_{3}(\mathrm{pH}=2.0$ was adjusted by adding $\left.\mathrm{H}_{2} \mathrm{SO}_{4}\right)$.

(b) Removal of AAO template (Figure 1b): In order to produce a free-standing Ni NWs, the as-deposited nanowires were dipped in a $10 \mathrm{M} \mathrm{NaOH}$ solution for $2 \mathrm{~h}$ to completely remove the AAO.

(c) Electrochemical modification (Figure 1c): The electrochemical modification of free-standing $\mathrm{Ni}$ NWs was performed in a solution composed of $0.5 \mathrm{M} \mathrm{KOH}$ by cyclic voltammetry $(\mathrm{CV})$ at scan rate $200 \mathrm{mV} \mathrm{s}^{-1}$. After the modification, the Ni NWs-based electrode was washed with a distilled water and ethanol and completely dried.

(d) Electro-oxidation of $\mathrm{HCHO}$ in alkaline media (Figure 1d): Free-standing $\mathrm{KOH}$-modified $\mathrm{Ni}$ nanowires $\left(\mathrm{Ni}(\mathrm{OH})_{2} / \mathrm{NiOOH}-\mathrm{Ni} \mathrm{NWs}\right.$ ) were used for electrochemical investigation (cyclic voltammetry and amperometry) of $\mathrm{HCHO}$ oxidation. The electrolyte solutions of $0.1-0.02 \mathrm{M} \mathrm{HCHO}$ and $0.1 \mathrm{M}$ $\mathrm{NaOH}(\mathrm{pH}=13.7)$ were prepared freshly for every set of experiments. The cyclic voltammograms were recorded from $0 \mathrm{~V}$ to $+1.0 \mathrm{~V}$ at a scan rate of $100 \mathrm{mV} \mathrm{s}^{-1}$. Amperometric measurements were executed under a constant potentials from $+0.7 \mathrm{~V}$ to $+1.0 \mathrm{~V}$ for $10 \mathrm{~s}$.

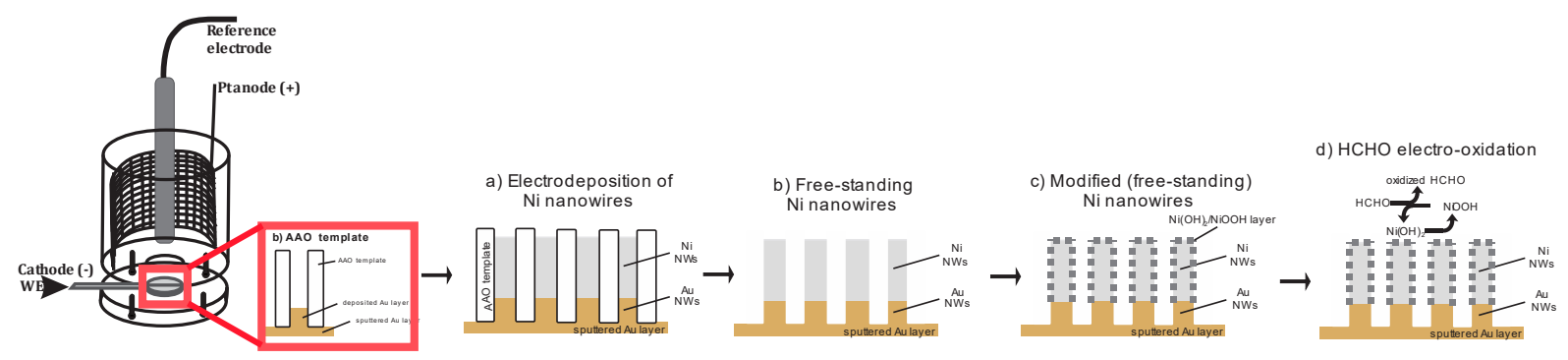

Figure 1. Scheme of the Teflon electrolytic cell and illustration of all experimental processes that were used before the studies of $\mathrm{HCHO}$ electro-oxidation.

The as-deposited Ni NWs were characterized using a field emission-gun scanning electron microscope (FEG-SEM) JEOL JSM-7600F equipped with an energy-dispersive X-ray spectroscopy (EDXS). The morphology of the $\mathrm{Ni}(\mathrm{OH})_{2} / \mathrm{NiOOH}-\mathrm{Ni} \mathrm{NWs}$ was investigated using the transmission electron microscope (TEM, Jeol JEM-2010F). 


\section{Results}

The Ni nanowires (NWs) for $\mathrm{HCHO}$ detection were prepared by electrodeposition of $\mathrm{Ni}$ into AAO template. Electrodeposited Ni nanowires (200 nm diameter, retaining the size $\sim 2-3 \mu \mathrm{m}$ ) were investigated using SEM and EDX analysis that revealed the presence of $\mathrm{Ni}$ in the completely filled pores of alumina template (Figure 1a). After the electro-deposition, the template was etched in strong alkaline solution in order to generate free-standing NWs (Figure 1b).

Furthermore, free-standing Ni NWs based electrode was modified in alkaline solution $(\mathrm{KOH})$ to form an active $\mathrm{Ni}(\mathrm{OH})_{2} / \mathrm{NiOOH}$ redox couple on the surface of $\mathrm{Ni}$ NWs-based electrode using cyclic voltammetry (Figure 1c). The TEM analysis revealed the amorphous nature of formed $\mathrm{Ni}(\mathrm{OH})_{2} / \mathrm{NiOOH}$ layer (thickness $\approx 10 \mathrm{~nm}$ ). Modified $\mathrm{Ni}$ NWs-based electrode $\left(\mathrm{Ni}(\mathrm{OH})_{2} / \mathrm{NiOOH}-\mathrm{Ni}\right.$ NWs) was further used as a receptor element for HCHO electro-oxidation (Figure 1d).

The investigation of the electrochemical behavior of $\mathrm{HCHO}$ electro-oxidation in $0.1 \mathrm{M} \mathrm{NaOH}$ solution on the $\mathrm{Ni}(\mathrm{OH})_{2} / \mathrm{NiOOH}-\mathrm{Ni} \mathrm{NWs}$-based electrode (i.e., receptor element) was carried out by cyclic voltammetry and amperometry. The receptor element responded to $\mathrm{HCHO}$ in a concentration range from $0.8 \mu \mathrm{M}$ to $0.2 \mathrm{mM}$ (Figure 2). Obtained results from cyclic voltammograms showed that $\mathrm{HCHO}$ oxidation peak current density increases drastically with increasing formaldehyde concentrations, but the onset potential shifted to more positive as a result of IR drop [8]. Also, a rise in the oxidation peak current is observed due to the oxidation of $\mathrm{NiOOH}$ species by HCHO. The increase in the current densities of oxidation peak is a consequence of the redox reaction between $\mathrm{Ni}(\mathrm{OH})_{2} / \mathrm{NiOOH}$ redox couple (on the surface of $\mathrm{Ni} \mathrm{NWs}$ ) and the $\mathrm{HCHO}$. The results indicate that $\mathrm{HCHO}$ is oxidized via a possible mechanism presented in Scheme 1 [7,9-13]. Amperometric measurements confirmed two broad linearity ranges (from $0.01-2 \mathrm{mM}$ and $2-20 \mathrm{mM}$ ) and fast response (3s). Taking into account the determined electrochemically active surface areas (Aecsa) (determined by oxalate method $[6,14]$ ) we have been able to calculate the sensitivities: $0.3419 \mathrm{~mA} \mathrm{~L} \mathrm{~cm}^{-2} \mathrm{mmol}^{-1}$ and $0.0458 \mathrm{~mA} \mathrm{~L} \mathrm{~cm}{ }^{-2} \mathrm{mmol}^{-1}$. The receptor element has a detection capabitility of $0.8 \mu \mathrm{mol} \mathrm{L}^{-1}$ (experimentally determined and calculated according to the IUPAC recommendation).

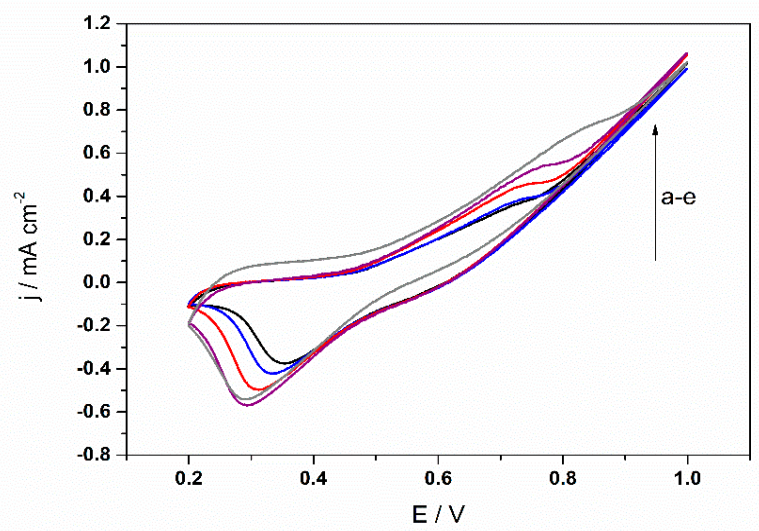

Figure 2. $\mathrm{CV}$ curves of the $\mathrm{Ni}(\mathrm{OH})_{2} / \mathrm{NiO}(\mathrm{OH})-\mathrm{Ni}$ NWs-based electrode, obtained at $\mathrm{v}=100 \mathrm{mV} \mathrm{s}^{-1}$ and room temperature in $0.1 \mathrm{~mol} \mathrm{~L}^{-1} \mathrm{NaOH}$ solution with different concentrations of HCHO: (a) 0.0 (black), (b) 0.001 (blue), (c) 0.5 (red), (d) 2.0 (purple) and (e) $20 \mathrm{mmol} \mathrm{L}^{-1}$ (grey). 


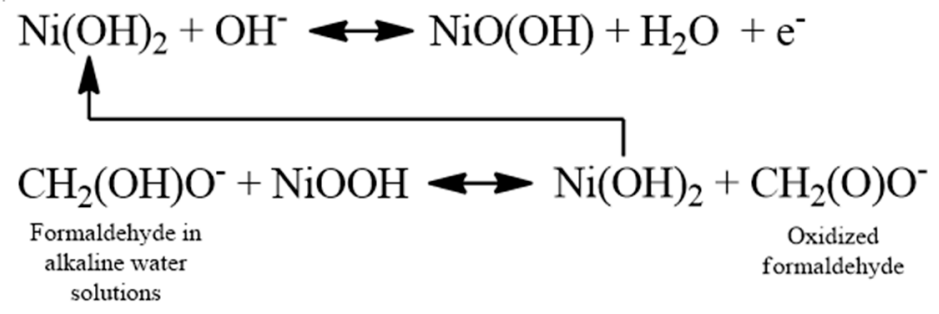

Scheme 1. Possible mechanism of $\mathrm{HCHO}$ electro-oxidation on $\mathrm{Ni}(\mathrm{OH})_{2} / \mathrm{NiOOH}-\mathrm{Ni} \mathrm{NWs}$ based electrode, i.e., receptor element.

\section{Conclusions}

This study reflects the ability to process the $\mathrm{Ni}(\mathrm{OH})_{2} / \mathrm{NiOOH}-\mathrm{Ni} \mathrm{NWs}$-based receptor elements via a cost effective template-assisted electrodeposition method followed by modification of the Ni surface in alkaline electrolyte. This approach enables an easy fabrication of a novel and efficient non-enzymatic sensor for the electro-oxidation of $\mathrm{HCHO}$ with good sensitivity and low detection limit $0.8 \mu \mathrm{mol} \mathrm{L} \mathrm{L}^{-1}$ which is comparable and even surpassing those achieved for nanostructured noble metals and other reported $\mathrm{Ni}-$ based electrodes.

Acknowledgments: This work was supported by Slovenian Research Agency (ARRS) [PR-06805].

\section{References}

1. Batista, E.; Iwasita, T. Adsorbed intermediates of formaldehyde oxidation and their role in the reaction mechanism. Langmuir 2006, 22, 7912-7916.

2. Hasanzadeh, M.; Khalilzadeh, B.; Shadjou, N.; Karim-Nezhad, G.; Saghatforoush, L.; Kazeman, I.; Abnosi, M.H. A New Kinetic-Mechanistic Approach to Elucidate Formaldehyde Electrooxidation on Copper Electrode. Electroanalysis 2010, 22, 168-176.

3. Burke, L.D. Scope for new applications for gold arising from the electrocatalytic behaviour of its metastable surface states. Gold Bull. 2004, 37, 125-135.

4. Bandodkar, A.J.; Wang, J. Non-invasive wearable electrochemical sensors: A review. Trends Biotechnol. 2014, 32, 363-371.

5. García, M.; Batalla, P.; Escarpa, A. Metallic and polymeric nanowires for electrochemical sensing and biosensing. Trac Trends Anal. Chem. 2014, 57, 6-22.

6. Hall, D.S.; Bock, C.; MacDougall, B.R. An oxalate method for measuring the surface area of nickel electrodes. J. Electrochem. Soc. 2014, 161, H787-H795.

7. Ojani, R.; Raoof, J.B.; Zavvarmahalleh, S.R.H. Preparation of Ni/poly (1,5-diaminonaphthalene)-modified carbon paste electrode; application in electrocatalytic oxidation of formaldehyde for fuel cells. J. Solid State Electrochem. 2009, 13, 1605-1611.

8. Rahim, M.A.; Hameed, R.A.; Khalil, M. Nickel as a catalyst for the electro-oxidation of methanol in alkaline medium. J. Power Sources 2004, 134, 160-169.

9. Hassaninejad-Darzi, S.K. A novel, effective and low cost catalyst for formaldehyde electrooxidation based on nickel ions dispersed onto chitosan-modified carbon paste electrode for fuel cell. J. Electroceramics 2014, $33,252-263$.

10. Raoof, J.-B.; Omrani, A.O.; Ojani, R.; Monfared, F. Poly( $N$-methylaniline)/nickel modified carbon paste electrode as an efficient and cheep electrode for electrocatalytic oxidation of formaldehyde in alkaline medium. J. Electroanal. Chem. 2009, 633, 153-158.

11. Ojani, R.; Raoof, J.-B.; Safshekan, S.; Electrocatalytic oxidation of formaldehyde on nickel modified ionic liquid carbon paste electrode as a simple and efficient electrode. J. Appl. Electrochem. 2012, 42, 81-87.

12. Raoof, J.-B.; Ojani, R.; Abdi, S.; Hosseini, S.R. Highly improved electrooxidation of formaldehyde on nickel/poly(o-toluidine)/Triton X-100 film modified carbon nanotube paste electrode. Int. J. Hydrog. Energy 2012, 37, 2137-2146. 
13. Azizi, S.N.; Ghasemi, S.; Amiripour, F. Nickel/P nanozeolite modified electrode: A new sensor for the detection of formaldehyde. Sens. Actuators B Chem. 2016, 227, 1-10.

14. Drunen, J.; Barbosa, A.F.; Tremiliosi-Filho, G. The Formation of Surface Oxides on Nickel in OxalateContaining Alkaline Media. Electrocatalysis 2015, 6, 481-491.

(C) 2019 by the authors. Licensee MDPI, Basel, Switzerland. This article is an open access article distributed under the terms and conditions of the Creative Commons Attribution (CC BY) license (http://creativecommons.org/licenses/by/4.0/). 